\title{
Strategic management accounting as an information platform for measuring innovation of the enterprise
}

\author{
Mykola Bondar $^{1}$, Natalia Iershova ${ }^{21}$, and Tetyana Chaika $^{2}$ \\ ${ }^{1}$ SHEI “Kyiv National Economic University named after Vadym Hetman”, 03057, Kyiv, Ukraine \\ ${ }^{2} \mathrm{NTU}$ “KhPI”, Institute of Economics, International Management and Marketing, 61002, Kharkiv, \\ Ukraine
}

\begin{abstract}
The study provides an integrated analysis system of the innovative activity of the enterprise, generalized mechanism of information processing in the accounting and analytical system of the enterprise. The role of information of strategic management accounting and analysis in the accounting and analytical system of the enterprise is substantiated. The bimodal methodological approach to measuring innovation of the enterprise on the basis of an integral performance exposure, calculated on a set of partial indicators, using additive method was introduced.
\end{abstract}

\section{Introduction.}

Long-term development of the enterprises in the dynamic market conditions directly depends on the state of innovative activity. The measuring innovation is a prerequisite for the production of innovations and is of interest to potential investors. Most of the specialists involved in the innovation field associate the innovation activity with the growth of the profitability level of the enterprise and the achievement of competitive advantages in the future, reflected in the Sustainable Development Strategy "Ukraine-2020". Measurement of innovative activity is the initial stage of planning of innovative activity and evaluation of innovative development of the enterprise as a whole. Therefore, its methodological and information provision is of particular importance.

Methods. The research methodology was based on the theory of innovation management, management accounting and strategic analysis. The main methods that formed the conceptual basis of the study are: comparison, analysis and synthesis, as well as expert, empirical generalization and statistical processing. Telephone interviewing, analysis of publicly disclosed information, data from the Internet and insider information were used. The methodical approach to measuring innovation of the enterprise is developed using the method of expert measurements, as well as polling.

\section{Results and discussion}

${ }^{1}$ Corresponding author: iershova.ny@gmail.com 


\section{Analysis of innovative activity of the enterprise - special aspects of implementation}

At present, there is no single methodology for analyzing the innovative activity of the enterprise due to the complexity of the development of the methodologies of the study, the availability of different approaches to defining the essence of the concept of "innovative activity of the enterprise", the problematic allocation of factors that affect the innovative activity of the enterprises [1-4]. The peculiarity of the analysis of the innovative activity of the enterprise is the coverage of all its stages, the orientation towards identifying the achievement of the main objectives of the enterprise, the close relationship with the system of strategic management and the adoption of long-term managerial decisions, the integration of quantitative and qualitative methods of analysis, methods of mathematical, logical analysis, methods of expert measurements (Fig. 1).

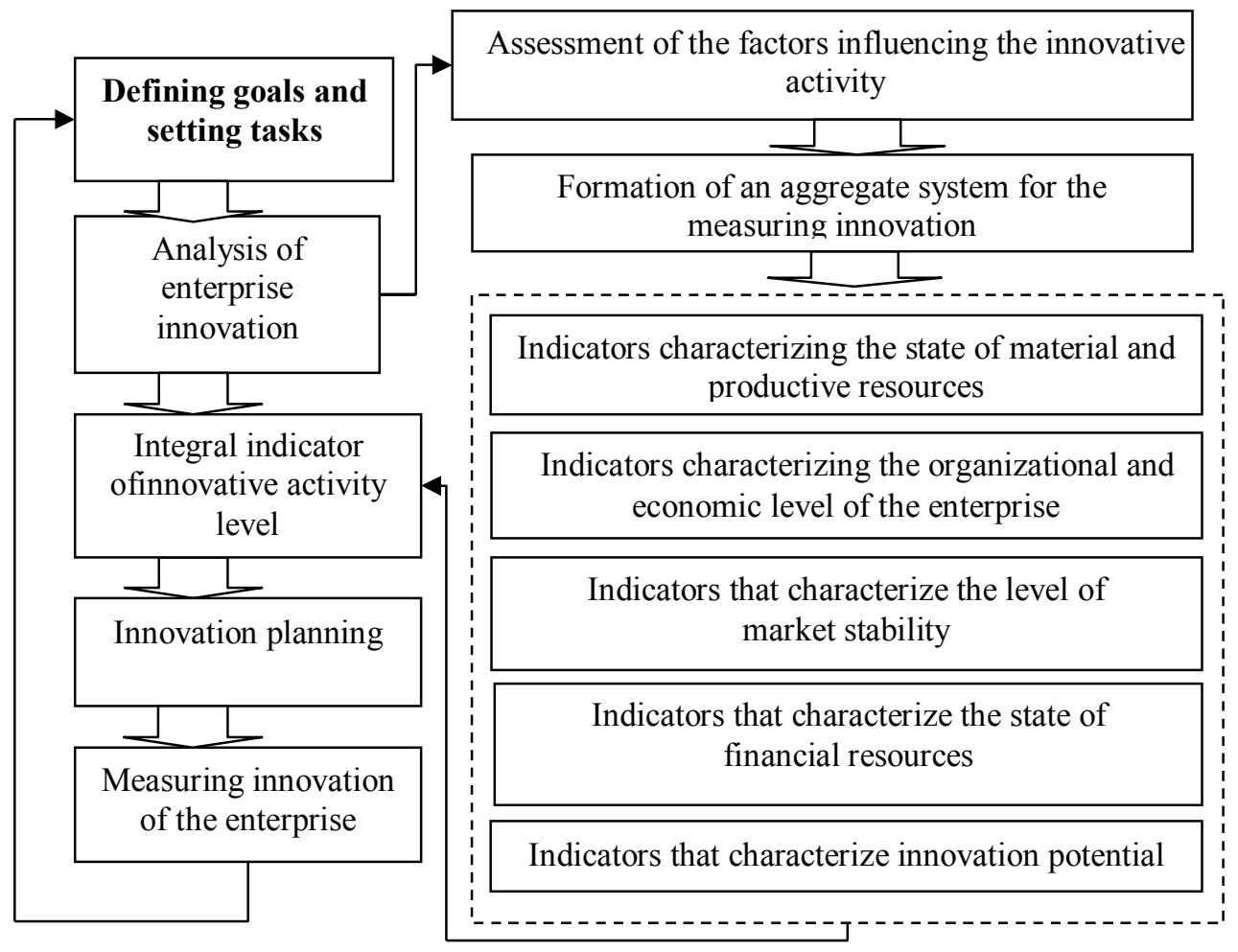

Fig. 1. Integrated analysis system of innovative activity of the enterprise

The complex model of the analysis of innovative activity of the enterprise characterizes innovation processes and investment decisions associated with them, therefore its results are useful in making managerial decisions concerning long-term sustainable development of the enterprise and achievement of the best results of production activity using available resources $[5,6]$.

\section{Strategic management accounting as an information platform for the analysis of innovative activity of the enterprise}


The main focus of strategic management accounting is the formation of financial and nonfinancial information when making strategic management decisions, including for a comprehensive analysis of innovative activity of the enterprises [7-9]. The attention has focused primarily on its external orientation, and information formed in the contour of strategic management accounting is different in nature, so for its processing used both accounting and special, including mathematical tools. Strategic management accounting is a component of the accounting and analytical system implemented in the enterprise (Fig. 2).

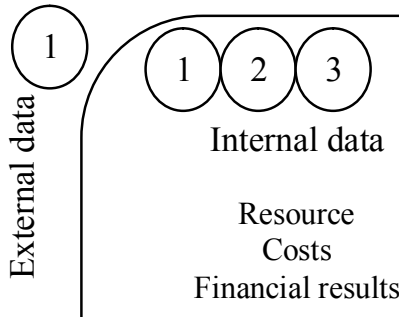

Exit
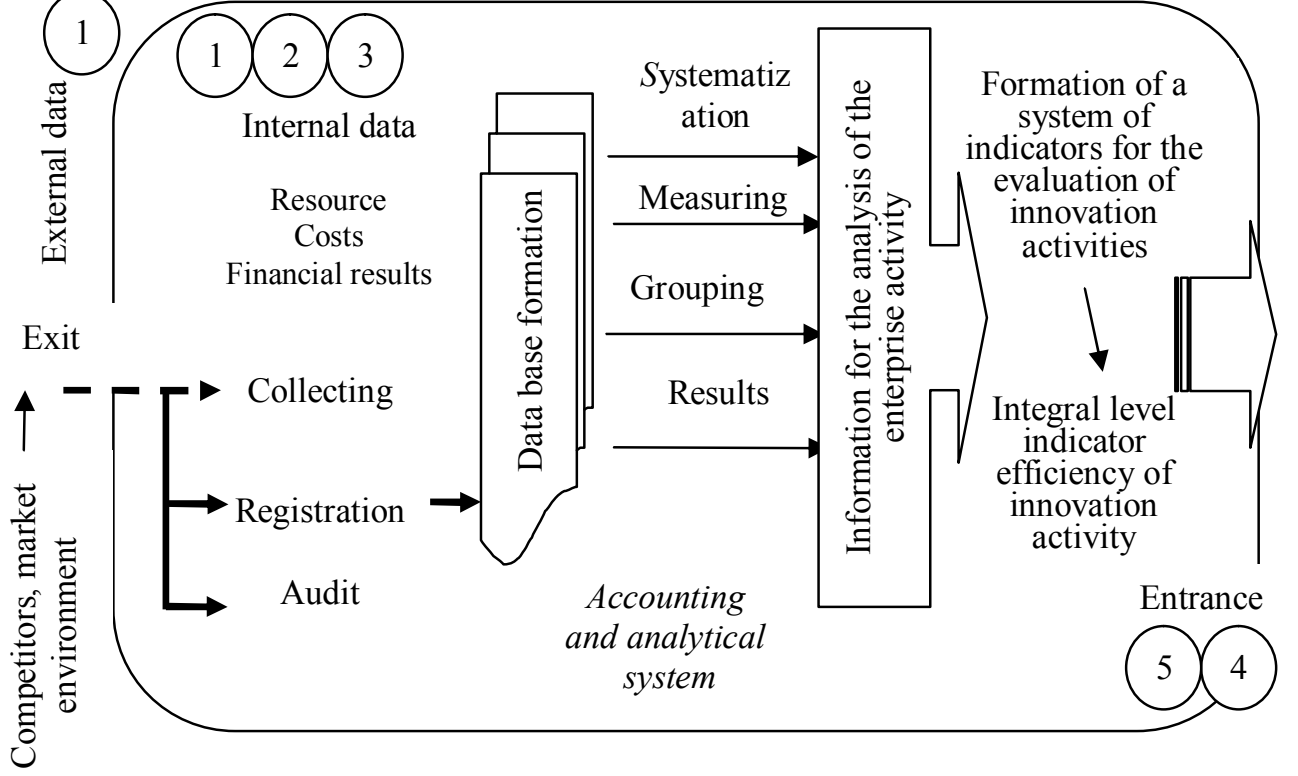

Entrance

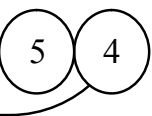

1 - strategic management accounting, 2 - accounting and management accounting, 3 - financial accounting, 4 - financial reporting, 5 - strategic management reporting

Fig. 2. The mechanism of information processing in the accounting and analytical system of the enterprise

In such a system, various content, quality, sources of formation of information are used and formed, which requires its timely collection, verification, analytical processing and preparation of analytical work outputs $[7,8]$.

\section{Measuring innovation of the enterprise}

This study proposes a bimodal measurement of innovation of the enterprise. The first level is the formation of aggregated indicators, $A i$. Each aggregate indicator is represented as a group of partial indicators that characterize its state, $G i$. The second is the calculation of the integral index, $I$. The aggregate indicators are: the level of material and technical provision $\left(A_{1}\right)$, market stability $\left(A_{2}\right)$, organizational and economic level of the enterprise $\left(A_{3}\right)$, the state of financial resources $\left(A_{4}\right)$, innovative potential $\left(A_{5}\right)$.

The partial indicators used for the measurement should be simple, understandable and consistent with the goals of information users. Therefore, at their formation, we suggest taking into account the practical aspect. At the same time, information congestion should be avoided, because too many components complicate the evaluation procedure. The choice of partial indicators, the formation of aggregate indicators is based on the method of expert measurements [10]. The score scale is used to measure partial indicators: 0 points - the indicator is well below the standard level (or higher if the excess of the norm is negative) or 
the dynamics of change during the reporting year is negative; 0.3 points - the indicator is close to the limits of normative values, or the dynamics of its change during the year is unchanged; 0.6 points - an indicator within the normative value, or the dynamics of its change during the year is insignificant; 1 point - an indicator within the normative value, or a significant positive dynamics of its change during the study period. The rates of growth of indicators are divided by the relative 5\%. Normative values of partial indicators are established on the basis of official statistical data, financial analysis techniques, expert experience and financial and managerial reporting data of the enterprise. Balance score, $\mathrm{G}_{\mathrm{i}}$

$$
\begin{aligned}
& A 1=\sum_{i=1}^{5} G_{i} \times k_{i} \\
& I=\sum_{i=1}^{5} A_{i} \times K_{i},[0 ; 1]
\end{aligned}
$$

Since the partial indicators as aggregated have different significance in the formation of indicators of a higher level, in the study, the authors calculated their importance. In calculating weight coefficients a method of questioning is used, according to which the impact of each indicator on the levels of innovation of the enterprise is estimated on the scale as follows: 0 - no impact; 1 - very weak impact; 2 - weak impact; 3 - medium impact; 4 - strong impact; 5 - very strong impact. Expert interviews are conducted in two stages: first, experts express their opinion on aggregate indicators, and then measure their components. Expert judgments are recorded

As a result, a matrix is formed, on the basis of which averaged expert opinion and weight coefficient are calculated for each indicator. Averaging the results obtained during the expert evaluation is carried out using methods of mean arithmetic or geometric mean. The modified Harrington verbal numeric rating scale was used in the study to interpret the results (Table 2).

Table 1. Description of the levels of innovative activity of the enterprise

\begin{tabular}{|c|c|l|}
\hline $\begin{array}{c}\text { Activity } \\
\text { level }\end{array}$ & $\begin{array}{c}\text { Integral } \\
\text { indicator }\end{array}$ & \multicolumn{1}{c|}{ Description } \\
\hline low & $0-0.24$ & $\begin{array}{l}\text { The organization of production processes is inefficient. There is a } \\
\text { lack of fixed assets and a shortage of own sources of financing. } \\
\text { Investments are almost used to finance current activity }\end{array}$ \\
\hline $\begin{array}{c}\text { minimum } \\
\text { allowable }\end{array}$ & $0.25-$ & $\begin{array}{l}\text { Due to lack of own funds, it is difficult to implement innovative } \\
\text { projects, which can not be financed without borrowing capital. } \\
\text { Innovation projects are characterized by low profitability and a } \\
\text { large number of them remains unrealized }\end{array}$ \\
\hline normal & $0.5-0.74$ & $\begin{array}{l}\text { Innovative projects of the enterprise are quite profitable, with an } \\
\text { acceptable payback period. The enterprise uses both its own and } \\
\text { borrowed funds to finance innovation. The dynamics of economic } \\
\text { indicators is characterized by low, but stable growth. Innovation } \\
\text { activity can be characterized as successful, but not sufficiently } \\
\text { sustainable }\end{array}$ \\
\hline high & $0.75-1$ & $\begin{array}{l}\text { The introduction of innovation projects is accompanied by a } \\
\text { tangible increase in economic performance and increased } \\
\text { competitiveness. The enterprise actively uses its own funds and has } \\
\text { opportunities for building up its production potential }\end{array}$ \\
\hline
\end{tabular}

The approbation of the introduced methodology for measuring innovation of the enterprise was carried out within the implementation of the scientific theme "Development of theoretical and methodological foundations for the formation of a management 
accounting system of the enterprise" (No. 0117U004814) by the Department of Economic Analysis and Accounting of NTU "KhPI". The sample includes four enterprises of Kharkiv, which are engaged in innovative activity, since the specifics of their activity requires continuous improvement of not only the production process, but also the system of management and quality of accounting and analytical provision. The information basis was the data of strategic management accounting, financial and internal management reporting. The expert group is composed of top managers, representatives of the analytical department of the enterprises selected for research and the lecturers of the Department with the total number of 11 people.

Based on the developed questionnaire, experts have developed a balanced system of partial and aggregate indicators. Calculations are carried out by the baseline method, intermediate calculations and calculation of the integral indicator of the levels of innovation of the enterprise by the introduced method. The results are presented in Fig. 3.

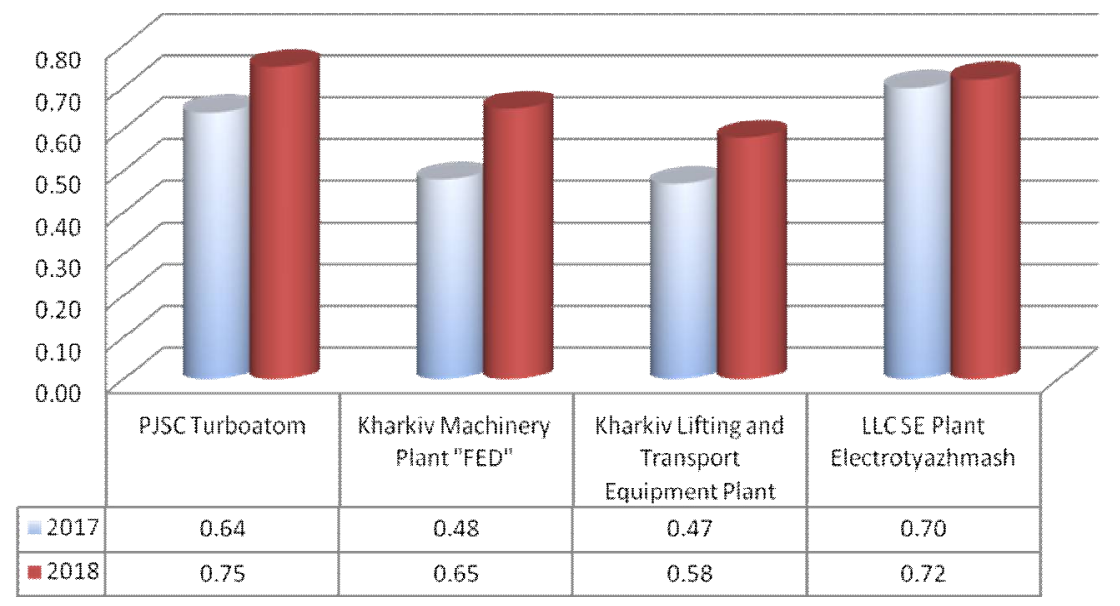

Fig. 3. The integral indicators of the levels of innovation of the enterprises

According to the results, none of the analyzed enterprises reached high levels of innovation. The normal levels of innovation are at PJSC Turboatom, SE Plant Electrotyazhmash. Each of the industrial enterprises that participated in the research suggested recommendations for the choice of further direction of innovation development. The developed method can also be used to forecast the innovative activity development of the analyzed enterprises.

\section{Conclusions}

The formed integrated analysis system of innovative activity of the enterprise clearly reflects the relationship of stages during its conduct with an orientation to achieve the main objectives of the enterprise, the integration of quantitative and qualitative methods of analysis. The presented mechanism of information processing in the accounting and analytical system of the enterprise reveals the role of information of strategic management accounting for the analysis of innovative activity of the enterprise. The introduced methodological approach to measuring innovation of the enterprise is based on a bimodal approach, which makes it possible to measure not only the levels of innovation of the enterprise as a whole, but also its individual components - the state of material and production resources, organizational and economic level of production, market stability, state of security financial resources, innovation potential. An approbation of the measuring 
innovation of the enterprise has been implemented on the data of industrial enterprises of Kharkiv.

\section{References}

1. O. Gadzevich, I. Matviychuk, Economic Journal Eastern Eur. National Univ. of L. Ukrainka, Methodology of analysis and evaluation of enterprise innovation, 3, 100104 (2017).

2. O. I. Tarasenko, O.M. Korolko, K.S. Belyavskaya Current problems of the economy, Estimation of Innovation Activity of the Enterprise in the System of Strategic Management, 9 (99), 133-141 (2009).

3. A. Kvitka, A. Kramarenko, Problems and Perspectives in Management, From big business to small and medium-sized enterprises: factors and prospect,. 2, 42-48 (2018).

4. G.V. Brik, Global and national problems of the economy, Accounting and analytical support of innovative activities of agricultural enterprises, 14, 905-909 (2016).

5. O. V. Portna Actual Problems of Economics, Assessment methodologies for aggregate financial potential of a country, 3(165), 106-112. (2015).

6. O. V. Portna, Actual Problems of Economics, The essence and the synergy effects of the architectonics of cumulative financial potential of the country, 10(172), 404-409 (2015).

7. M. Bondar, N. Iershova, Baltic Journal of Economic Studies, Strategic management object as an object of scientific research, 1, 47-54 (2015).

8. N. U. Ershova, Actual Problems of Economics, The quality of accounting information: methodological approach to assessment 8(158), 368-374, (2014).

9. I. Melnichuk, Global and national problems of the economy, Problems and Prospects of Improvement of Accounting and Analytical Support of Innovation Activities, 7, 845848 (2015).

10. N. Liba Economic analysis, Accounting and analytical support of innovation activity, 11, 247-251 (2012). 